\title{
A systematic review and meta-analysis of the survival rate of implants placed in previously failed sites
}

\section{Giovane Hisse GOMES(a) Mônica Yuri Orita MISAWA ${ }^{(a)}$ Carolina FERNANDES(a) Claudio Mendes PANNUTI(a) Luciana SARAIVA(a) GuY HUYNH-BA(b) Cristina Cunha VILLAR ${ }^{(a)}$}

(a) Universidade de São Paulo - USP, School of Dentistry, Department of Stomatology, University of São Paulo, São Paulo, São Paulo, Brazil.

(b) University of Texas Health Science Center, San Antonio Dental School, Department of Periodontics, San Antonio, TX, USA.

Declaration of Interests: The authors certify that they have no commercial or associative interest that represents a conflict of interest in connection with the manuscript.

Corresponding Author:

Cristina Cunha Villar

E-mail: villar@usp.br

htrps://doi.org/10.1590/1807-3107bor-2018.vol32.0027

Submitted: January 31, 2018

Accepted for publication: February 22, 2018

Last revision: February 23, 2018

\begin{abstract}
The aim of this study was to conduct a systematic review and meta-analysis to assess the clinical outcomes of dental implants placed in previously early and late implant failed sites. An electronic literature search was conducted in several databases for articles published up to February 2018. Human clinical trials that received at least one implant in a previously failed site were included. Hence, the PICO question that was aimed to be addressed was: Do patients undergoing implant replacement (second and third attempts) in previous failed sites have survival rates similar to implants placed at first attempts? A random effects model was used to calculate survival weighted means and corresponding 95\% Confidence Intervals (CI) among studies. Eleven studies of low to moderate methodological quality were included in this review. Implants placed in sites with history of one and two implant failures had a weighted survival rate (SR) of $88.7 \%$ (95\%CI 81.7-93.3) and $67.1 \%$ (95\%CI 51.1-79.9), respectively. Implants placed in sites with a previous early failure revealed a weighted SR of 91.8\% (95\%CI 85.1-95.6). First implants presented higher SR than implants placed in sites with one or two previous implant failures. In contrast, implants placed in sites with one and two implant failures had similar SR. Within its limitations, this review suggests that replacement implants have moderate SR. Larger prospective studies with well-defined criteria for early and late implant failure are necessary to confirm and expand on these results.
\end{abstract}

Keywords: Dental Implants; Survival Rate; Review.

\section{Introduction}

Although osseointegrated implants are routinely used for the rehabilitation of partially or totally edentulous patients, presenting high long-term survival rates, ${ }^{1,2,3,4}$ biological and technical complications may result in implant failure and loss. ${ }^{5}$ Implant failures have been reported in frequencies varying from $1 \%$ up to $22 \% .{ }^{1,2,3,4}$ Factors affecting implant failure are diverse and are related to patient systemic status, age and social habits, implant macro-/micro-design and surface chemical composition, implant position, bone quality, and surgical technique. ${ }^{6,78}$ Implant failures have been classified as early or late depending on its time of occurrence. ${ }^{5}$ Early failures occurring before or at abutment connection, as an inability 
to establish intimate bone-to-implant connection, ${ }^{4}$ and late failures occurring after prosthetic loading and related mainly to plaque-induced peri-implantitis and, possibly, to occlusal overloading. ${ }^{9}$

In some cases, implant replacement is the only treatment that allows fixed rehabilitation in sites with previous implant failure. ${ }^{10}$ In other instances, it is considered the therapy of choice owing to superior occlusal stability, ${ }^{11,12}$ masticatory efficiency and personal self-esteem provided by dental implants, ${ }^{13,14,15,16,17}$ without damaging adjacent teeth. Nonetheless, implant replacement still represents a challenging scenario. ${ }^{18}$

Although a number of retrospective cohort studies $18,19,20,21,10,22,23,24,25,26$ and one prospective clinical trial ${ }^{27}$ have evaluated survival rates of implants placed at sites with history of implant failure, these studies included limited numbers of patients. As such, the precise prognosis of implants placed at failed sites remains unclear. A recent meta-analysis conducted by Quaranta et al. ${ }^{28}$ showed that the survival rates of implants placed in the sites of previously failed implants are low. However, the specific prognosis of implants placed in sites with history of early and late implant failed remains to be determined. Therefore, the main aim of this study was to conduct a systematic review and meta-analysis to evaluate the survival of dental implants placed in previously early and late implant failed sites. The following focused question was addressed: "Do patients undergoing implant replacement (second and third attempts) in previous failed sites have survival rates similar to implants placed at first attempts?

\section{Methodology}

\section{Protocol and registration}

The study protocol of this systematic review and meta-analysis was registered at the National Institute for Health Research PROSPERO, International Prospective Register of Systematic Reviews (registration number 51293). The text was structured in accordance to the Preferred Reporting Items for Systematic Reviews and Meta-Analyses (PRISMA) statement guidelines. ${ }^{29}$

\section{Eligibility criteria}

\section{Type of studies and participants}

Controlled clinical trials, retrospective studies and prospective case series that received at least one implant in a previously failed site were considered eligible for inclusion.

\section{Exclusion criłeria}

Studies that included patients who had received replacement implants in sites other than the failed ones were excluded. Animal studies and case reports were also excluded.

\section{Intervention and comparison}

Survival rates of implants placed in sites with early and late implant failure.

\section{Outcome measures}

The primary outcome was the survival rate of implants placed in previously early and late failed sites.

\section{Information sources and search strategy}

Search strategies were developed for MEDLINE, Embase, Lilacs, SciELO, Scopus, Web of Science databases, as well as the grey literature. Medical subject headings (MeSH) terms were combined with Boolean operators and used to search the databases. All searches were performed without language restriction, up to February 2018. The following keywords and MeSH terms were used: ((“'dental implantation, endosseous" [mh] OR "dental implants"[mh])) AND $((($ replantation $[\mathrm{mh}])$ or (failed implant [tiab]) or (implant replacement [tiab]) NOT ("animals"[mh]). The electronic search was complemented by manual searches of reference lists from selected full-articles.

\section{Study selection}

Two calibrated reviewers (CCV and CF) screened independently titles and abstracts. Studies meeting the inclusion criteria, or those with insufficient information in the title and abstract to make a clear decision, were selected for further evaluation. Disagreements were solved by a discussion between the reviewers. All studies that met the inclusion criteria underwent a validity assessment. 


\section{Data collection, risk of bias assessment in individual studies}

Data collection and quality assessment of included studies were performed independently by two reviewers (CCV and $\mathrm{CF}$ ), using the modified Newcastle-Ottawa Scales (NOS). ${ }^{30}$ Disagreements were solved by discussion with a third reviewer (CMP).

\section{Summary measures and synthesis of results}

Inter-investigator reliability was assessed using kappa coefficient. Data from all studies examining the survival rate of implants placed in sites with history of one and two implant failures were pooled and analyzed using statistical analysis software (Comprehensive Meta-Analysis software, v.3.3.070, Englewood, USA). ${ }^{\S}$ A random effects model was used to calculate the weighted means and corresponding 95\% Confidence Intervals (CI) among the studies. Statistical heterogeneity and consistency among the studies was assessed with I. ${ }^{2}$

\section{Results}

\section{Study selection}

The computerized search strategy yielded 45 citations, of which 17 were screened for potentially meeting the inclusion criteria $(\kappa=0.61$; Figure 1). Independent screening of abstracts led to rejection of six citations ( $\kappa=0.689$; Figure 1$)$. Full texts of the remaining eleven publications were obtained for review and possible inclusion. Out of these, all articles were included $(\kappa=1.00) .18,19,20,21,10,27,22,23,24,25,26$

\section{Study characteristics}

Characteristics of the final 11 studies are reported in Table 1. Outcomes of implants placed at sites with history of one implant failure were reported in ten studies (Table 2), while outcomes of sites with two implant failures were reported by five studies (Table 3).

\section{Implants placed at sites with history of one implant failure}

Studies provided data on 579 patients treated with 704 replacement implants (Table 2). Time interval between removal of failed implants and placement of

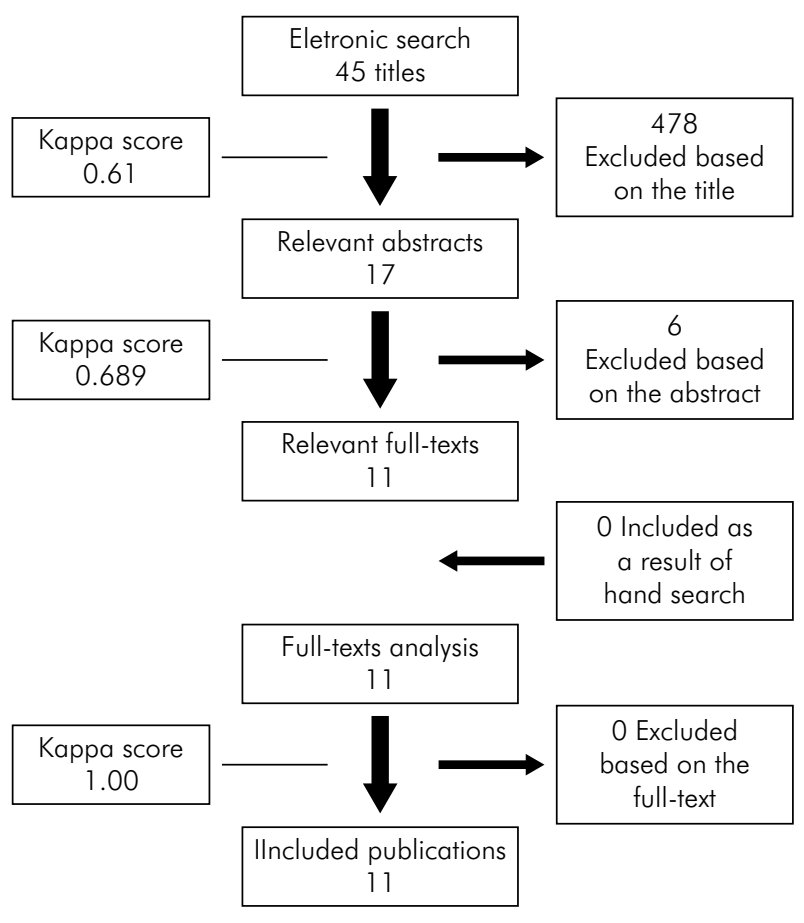

Figure 1. Simplified search strategy outline.

the replacement implant varied significantly, ranging from 0 (immediate replacement) to 132.8 months (Table 2). Replacement implants were followed for less than 1 year in two studies,,$^{23,25}$ and for at least 1 year in seven studies. ${ }^{18,19,20,21,10,27,24}$ In of one study, the observation period of replacement implants was not reported ${ }^{26}$ (Table 2).

Out of the 704 replacement implants placed in sites with history of one implant failure, 94 failed (Table 2), leading to a weighted survival rate of $88.7 \%$ for these implants (95\%CI: 81.7-93.3; $\mathrm{I}^{2}=78 \%$, $\mathrm{p}=0.000$ ) (Figure 2A). According to the studies that reported the time of the replacement implant failure, most occurred within the first months of follow up, but ranged from 1 to 158.9 months (Table 2). Second failure reasons and types were reported solely in two studies ${ }^{20,10}$ and most were classified as late. The causes for replacement implants loss were lack of osseointegration, peri-implantitis, occlusal overload or unknown causes (Table 2).

Only three studies reported on success rates of implants placed in sites with history of one implant failure. ${ }^{20,27,25}$ The random effects model revealed a weighted success rate of $85.0 \%$ for 


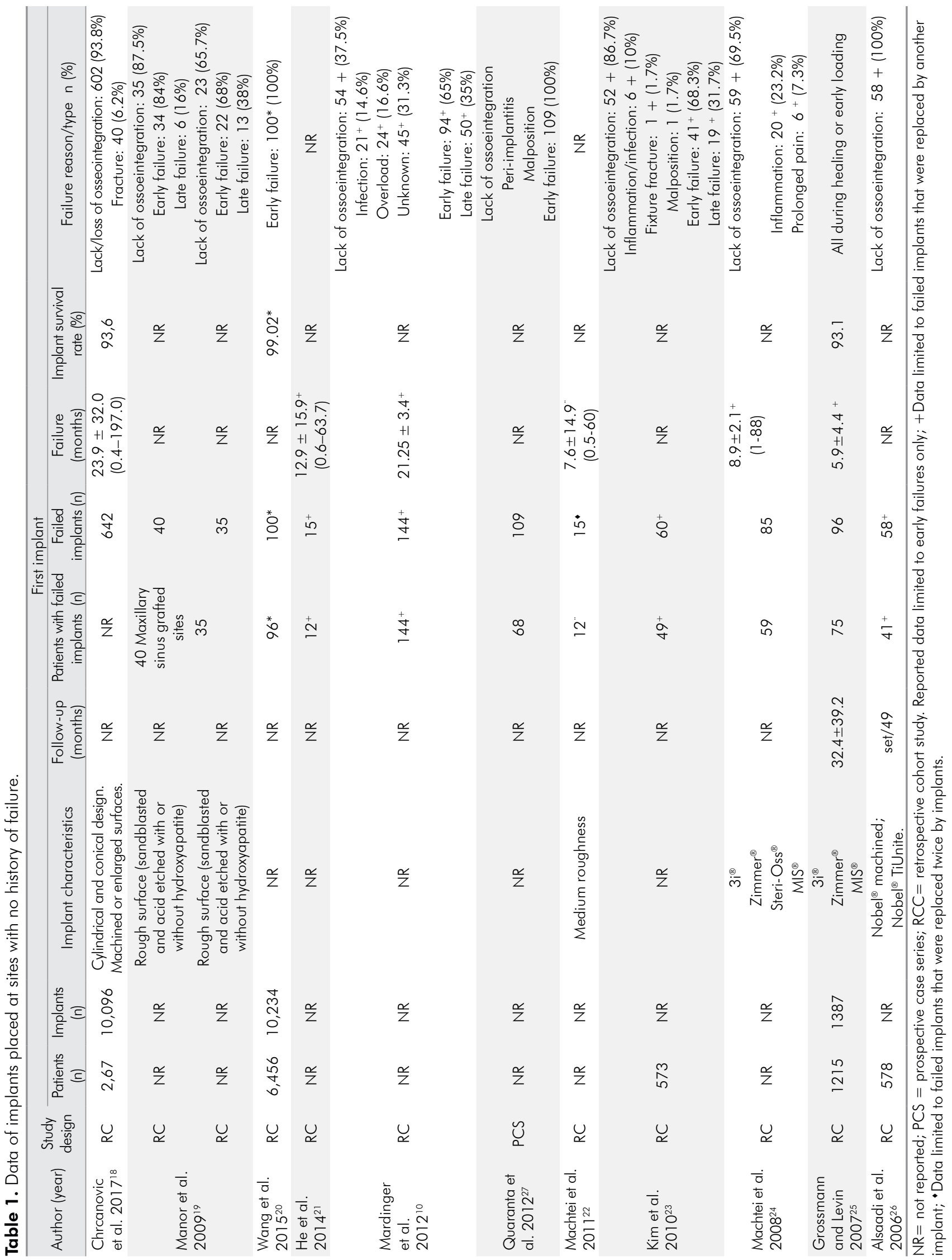




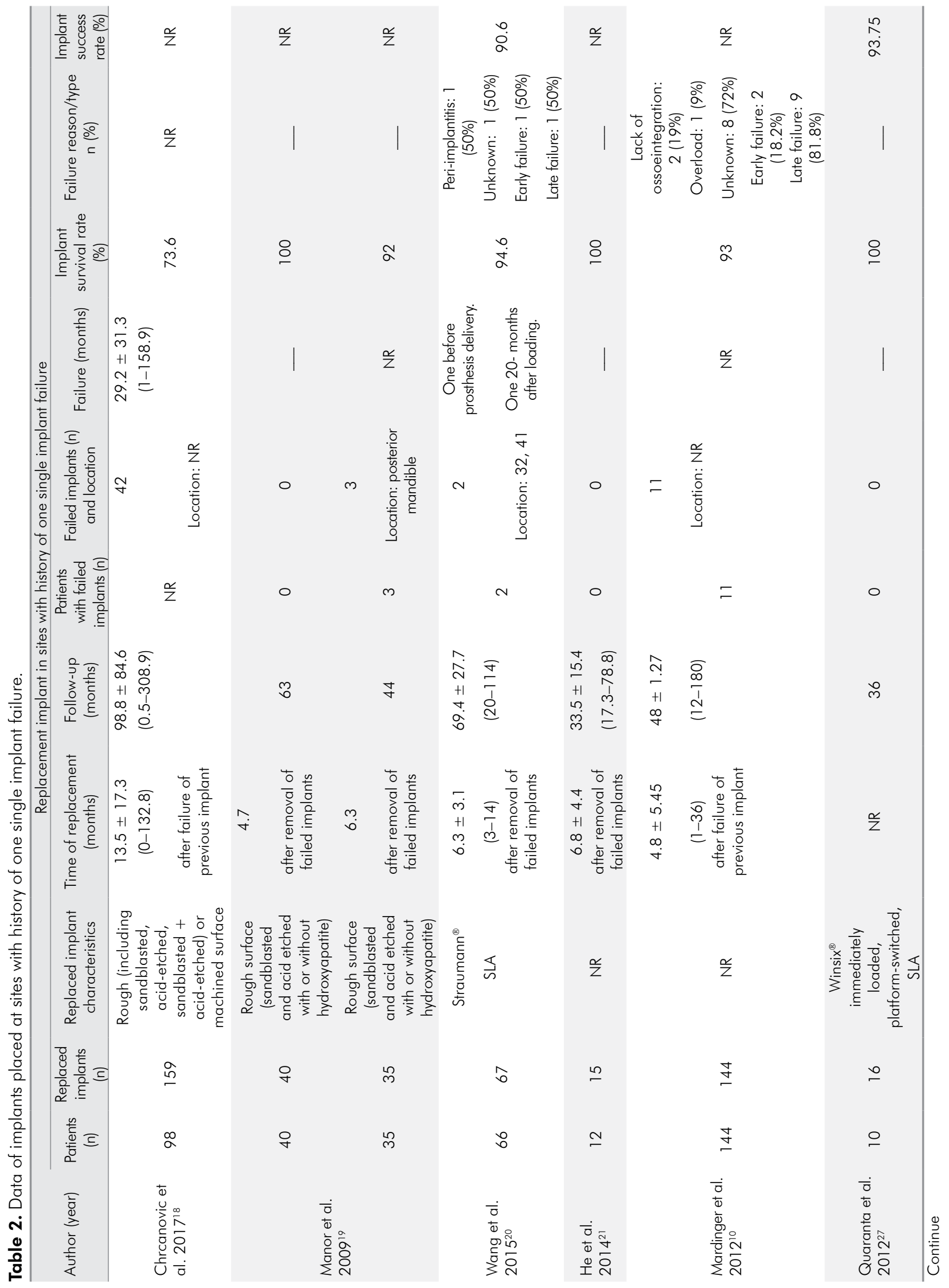




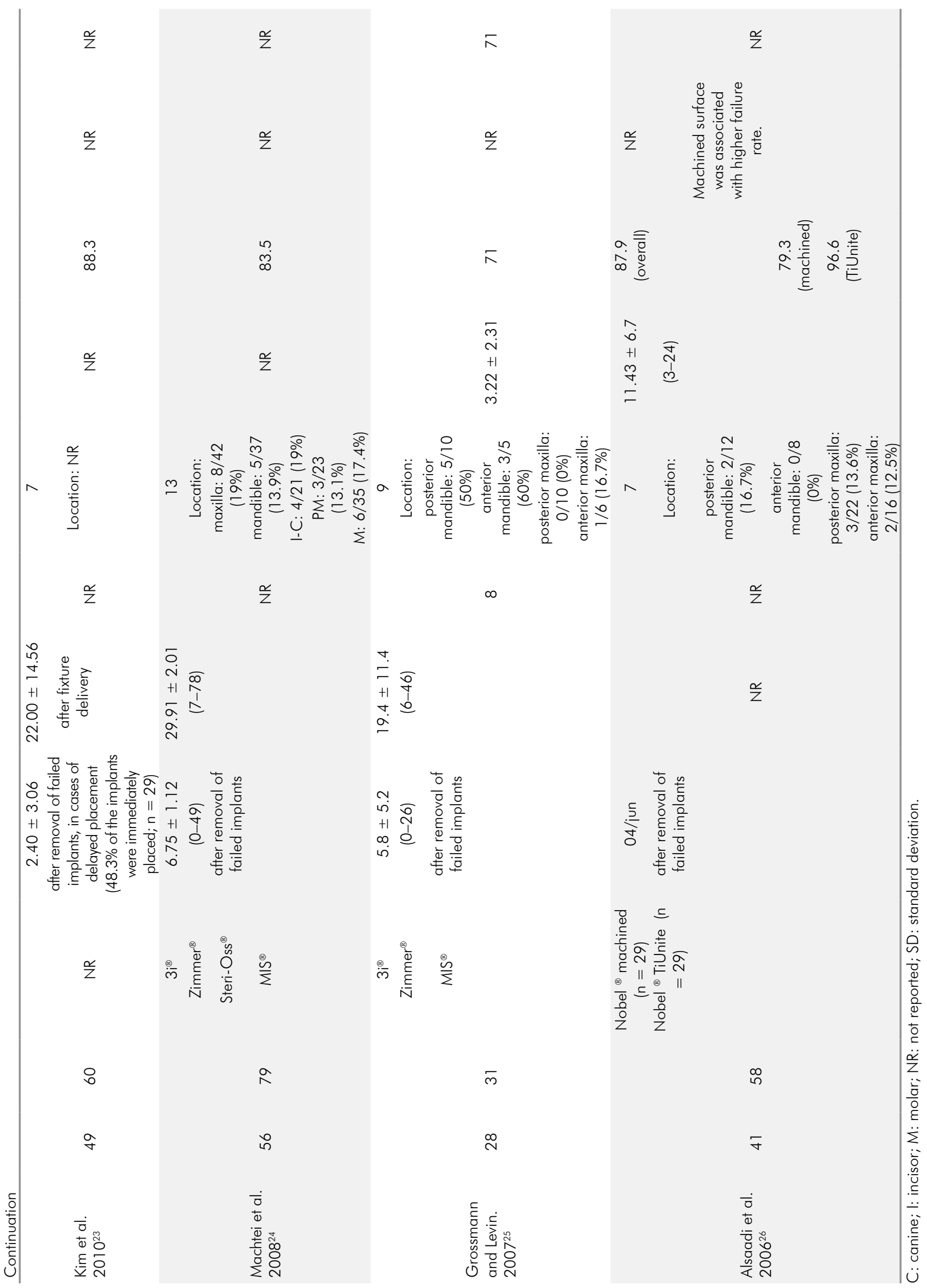


Gomes GH, Misawa MY, Fernandes C, Pannuti CM, Saraiva L, Huynh-Ba Get al.

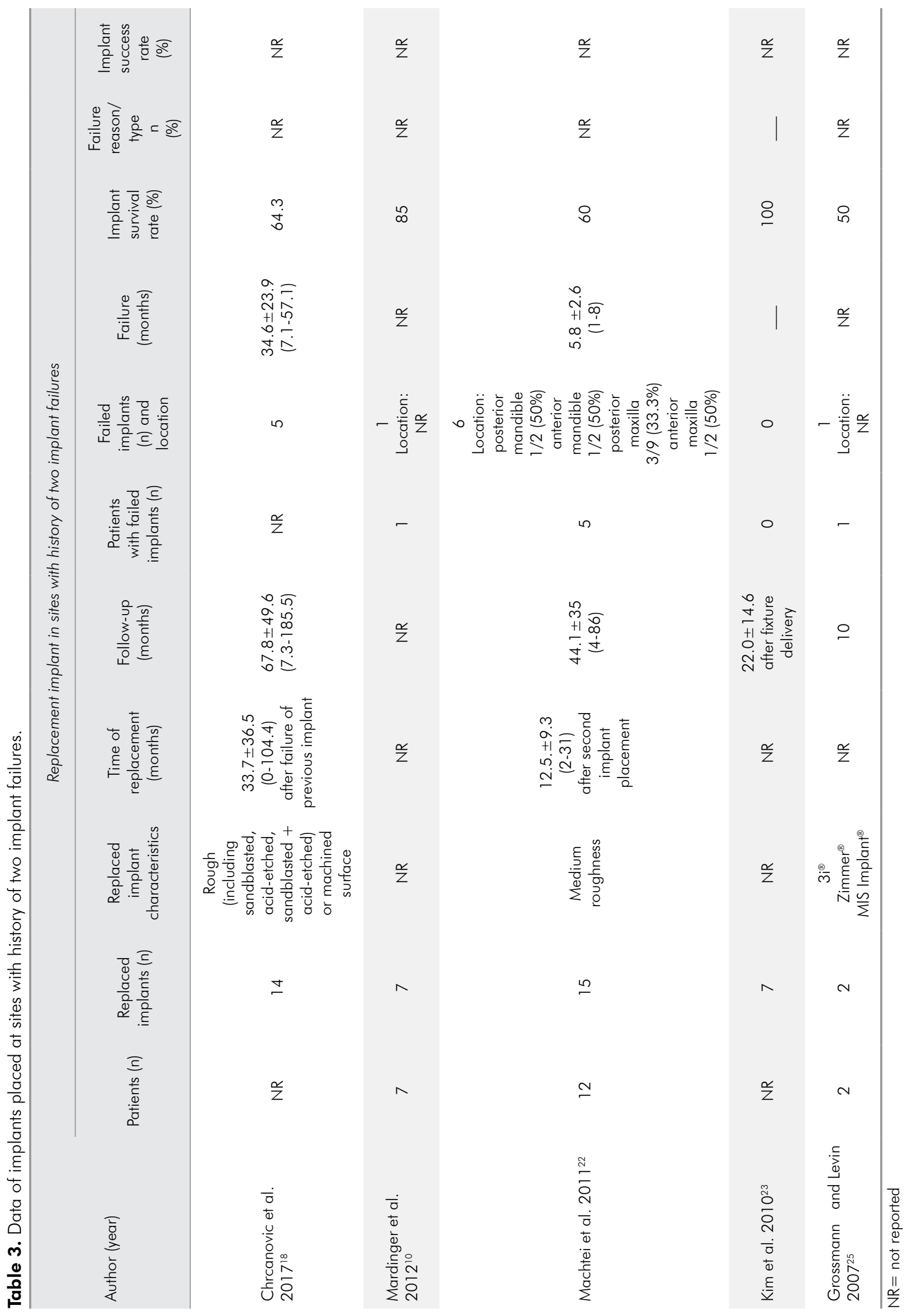


A systematic review and meta-analysis of the survival rate of implants placed in previously failed sites

\begin{tabular}{|c|c|c|c|c|c|c|c|}
\hline \multirow{2}{*}{ Study name } & \multicolumn{5}{|c|}{ Statistics for each study } & \multirow{2}{*}{ Event rate and $95 \% \mathrm{Cl}$} & \multirow{2}{*}{ Relative weight } \\
\hline & Event rate & Lower limit & Upper limit & Z-value & $\mathrm{p}$-value & & \\
\hline Alsaadi 2006 & 0.879 & 0.768 & 0.941 & 4.927 & 0.000 & & 11.84 \\
\hline Grossman \& Levin 2007 & 0.710 & 0.530 & 0.841 & 2.259 & 0.024 & & 11.94 \\
\hline Machtei 2008 & 0.835 & 0.737 & 0.902 & 5.354 & 0.000 & & 13.17 \\
\hline Kim 2010 & 0.883 & 0.775 & 0.943 & 5.034 & 0.000 & & 11.85 \\
\hline Quaranta 2012 & 0.971 & 0.664 & 0.998 & 2.436 & 0.015 & - & 3.19 \\
\hline Mardinger 2012 & 0.924 & 0.867 & 0.957 & 7.945 & 0.000 & & 13.03 \\
\hline $\mathrm{He} 2014$ & 0.969 & 0.650 & 0.998 & 2.390 & 0.017 & & 3.19 \\
\hline Wang 2015 & 0.970 & 0.888 & 0.993 & 4.849 & 0.000 & & 7.87 \\
\hline Manor 2016 & 0.960 & 0.883 & 0.967 & 5.393 & 0.000 & & 9.37 \\
\hline \multirow[t]{2}{*}{ Chrcanovic 2016} & 0.736 & 0.662 & 0.799 & 5.696 & 0.000 & & 14.55 \\
\hline & 0.887 & 0.817 & 0.933 & 7.163 & 0.000 & & \\
\hline a) & & & & & & $\begin{array}{llll}1.00 & 0.50 & 0.00 & 0.50\end{array}$ & 1.00 \\
\hline
\end{tabular}

\begin{tabular}{|c|c|c|c|c|c|c|}
\hline \multirow{2}{*}{ Study name } & \multicolumn{5}{|c|}{ Statistics for each study } & \multirow{2}{*}{ Event rate and $95 \% \mathrm{Cl}$} \\
\hline & Event rate & Lower limit & Upper limit & Z-value & $\mathrm{p}$-value & \\
\hline Grossman \& Levin 2007 & 0.710 & 0.530 & 0.841 & 2.259 & 0.024 & \\
\hline Quaranta 2012 & 0.938 & 0.665 & 0.991 & 2.622 & 0.009 & \\
\hline \multirow[t]{2}{*}{ Wang 2015} & 0.896 & 0.797 & 0.949 & 5.379 & 0.000 & \\
\hline & 0.850 & 0.663 & 0.942 & 3.211 & 0.001 & \\
\hline b) & & & & & & $\begin{array}{lllll}1.00 & 0.50 & 0.00 & 0.50 & 1.00\end{array}$ \\
\hline
\end{tabular}

\begin{tabular}{|c|c|c|c|c|c|c|c|c|c|}
\hline \multirow{2}{*}{ Study name } & \multicolumn{6}{|c|}{ Statistics for each study } & \multirow{2}{*}{\multicolumn{2}{|c|}{ Event rate and $95 \% \mathrm{Cl}$}} & \multirow{2}{*}{ Relative weight } \\
\hline & Event rate & Lower limit & Upper limit & Z-value & $\mathrm{p}$-value & Total & & & \\
\hline Alsaadi 2006 & 0.879 & 0.768 & 0.941 & 4.927 & 0.000 & $51 / 58$ & & & 71.73 \\
\hline Quaranta 2012 & 0.971 & 0.664 & 0.998 & 2.436 & 0.015 & $16 / 16$ & & $=$ & 5.66 \\
\hline \multirow[t]{2}{*}{ Wang 2015} & 0.970 & 0.888 & 0.993 & 4.849 & 0.000 & $65 / 67$ & & $\rightarrow$ & 22.61 \\
\hline & 0.918 & 0.851 & 0.956 & 7.058 & 0.000 & & & & \\
\hline c) & & & & & & & 1.00 & $\begin{array}{lll}0.50 & 0.00 & 0.50\end{array}$ & 1.00 \\
\hline
\end{tabular}

\begin{tabular}{|c|c|c|c|c|c|c|c|c|}
\hline \multirow{2}{*}{ Study name } & \multicolumn{5}{|c|}{ Statistics for each study } & \multirow{2}{*}{\multicolumn{2}{|c|}{ Event rate and $95 \% \mathrm{Cl}$}} & \multirow{2}{*}{ Relative weight } \\
\hline & Event rate & Lower limit & Upper limit & Z-value & $\mathrm{p}$-value & & & \\
\hline Grossman \& Levin 2007 & 0.500 & 0.059 & 0.941 & 0.000 & 1.000 & & $\longrightarrow$ & 5.79 \\
\hline Kim 2010 & 0.938 & 0.461 & 0.996 & 1.854 & 0.064 & & $\longrightarrow$ & 5.43 \\
\hline Machtei 2011 & 0.600 & 0.348 & 0.808 & 0.769 & 0.442 & & & 41.67 \\
\hline Mardinger 2012 & 0.857 & 0.419 & 0.980 & 1.659 & 0.097 & & -1 & 9.92 \\
\hline \multirow[t]{2}{*}{ Chrcanovic 2016} & 0.643 & 0.376 & 0.843 & 1.054 & 0.292 & & & 37.20 \\
\hline & 0.671 & 0.511 & 0.799 & 2.094 & 0.036 & & & \\
\hline d) & & & & & & 1.00 & $\begin{array}{lll}0.50 & 0.00 & 0.50\end{array}$ & 1.00 \\
\hline
\end{tabular}

Figure 2. Survival and success rates of replacement implants. A) Weighted survival rate of implants placed at sites with history of one implant failure. B) Weighted success rate of implants placed at sites with history of one implant failure. C) Weighted survival rate of implants placed at sites with history of one early implant failure. D) Weighted survival rate of implants placed at sites with history of two implant failures. 
these implants (95\%CI: 66.3-94.2; $\mathrm{I}^{2}=67.85 \%$, $\mathrm{p}=0.045$ ) (Figure 2B). Success criteria, however, was not disclosed in one study, ${ }^{25}$ and the other two studies adopted distinct success classifications: Wang et al. ${ }^{20}$ considered success as absence of pain, mobility, history of exudates, and bone loss around implants not exceeding $2 \mathrm{~mm}$; while Quaranta et al. ${ }^{27}$ used the criteria proposed by Albrektsson et al. ${ }^{31}$ Studies reporting exclusively on implants placed in sites with history of one early implant failure revealed a weighted implants survival rate of $91.8 \%$ (95\%CI: 85.1-95.6; $\mathrm{I}^{2}=48,80 \%, \mathrm{p}=0,14$ ) (Figure 2C). ${ }^{20,27,26}$ Implant success rate in these studies varied from 71 to $93.75 \%$ (Table 2). ${ }^{20,27}$ None of the studies reported the outcomes of implants placed exclusively in sites with history of late implant failure.

A weighted comparative analysis of the survival rate of replacement implants placed immediately after removal of failed implants and that of delayed replacement implants placed after healing of failed sites was not performed, as this comparison was addressed by only one study, ${ }^{23}$ in which survival rates of immediate and delayed replacement implants did not differ statistically $(90.9 \%$ and $86.8 \%$, respectively; $p=0.433$ ).

\section{Implants placed at sites with history of two implant failures}

Five studies reported outcomes of 45 replacement implants placed at sites with history of two implant failures (Table 3). Time of implant replacement was reported in only two studies (Table 3). ${ }^{18,22}$ These last implants were followed up to 185.5 months (Table 3).

Out of the 45 implants placed at sites with history of two implant failures, 13 failed (Table 3). The random effects model revealed a weighted survival rate of 67.1\% (95\%CI: 51.1-79.9; I2=0.00\%, $\mathrm{p}=0.47$ ) (Figure 2D). Only one study reported on the type of the failures, ${ }^{18}$ and implant success rates were not reported.

\section{Patient characteristics}

Patient characteristics varied considerably among the studies. Several studies excluded patients with a) systemic conditions likely to affect bone metabolism, 19,20,10,22,23,24 $\mathrm{b}$ ) changes in environmental conditions known to affect the outcome of implant therapy (smoking cessation or onset), ${ }^{24} \mathrm{c}$ ) behavioral conditions (poor oral hygiene, drug abuse habits), ${ }^{27} \mathrm{~d}$ ) parafunctional habits, ${ }^{24,27}$ and e) heavy smoking habits. ${ }^{20,23}$

According to results from other studies, no correlations were found between replacement implant failure and a) smoking, ${ }^{20,10,22,24}$ and b) American Society of Anesthesiologists (ASA) Physical Status classification system. ${ }^{10}$ However, a higher rate of replacement implant failure was described for patients taking antidepressants and antithrombotic agents. ${ }^{18}$ Moreover, local bone characteristics such as poor quality and low quantity have also been associated with higher replacement implant failure. ${ }^{18}$

\section{Replacement implants characteristics}

Surface of replacement implants were reported in six studies, analyzing medium rough, ${ }^{18,19,22}$ SLA, ${ }^{20,27}$ TiUnite and machined surfaces. ${ }^{18,26}$ Only two studies compared the survival rates of smooth- or rough-surface replacement dental implants, ${ }^{18,26}$ demonstrating that the survival rate of rough replacement implants was significantly higher than that of machined implants.

\section{Comparison of the survival rates of implants placed in sites with or without history of implant failure}

Due to the large heterogeneity among studies, comparisons of the survival rates of implants placed in sites with history of none, one or two implant failures included only same-study comparative data. Only three studies disclosed the survival rates of implants placed in sites of pristine bone (first implant) and with history of one implant failure. ${ }^{18,20,25}$ According to a metaanalysis of these studies, first implants had higher survival rates than implants placed in sites with one previous implant failure $(96 \%$ and $79 \%$, respectively; odds ratio $(\mathrm{OR})=5.19(3.77-7.16)$. A lack of a sufficient number of studies precluded a comparison between the survival rates of first implants and implants placed at a site with history of one early failure.

A meta-analysis of the data from two studies that compared survival rates of first implants and implants placed in sites with history of two implant failure ${ }^{18,25}$ revealed that the survival rate of first implants was higher than that of implants placed 


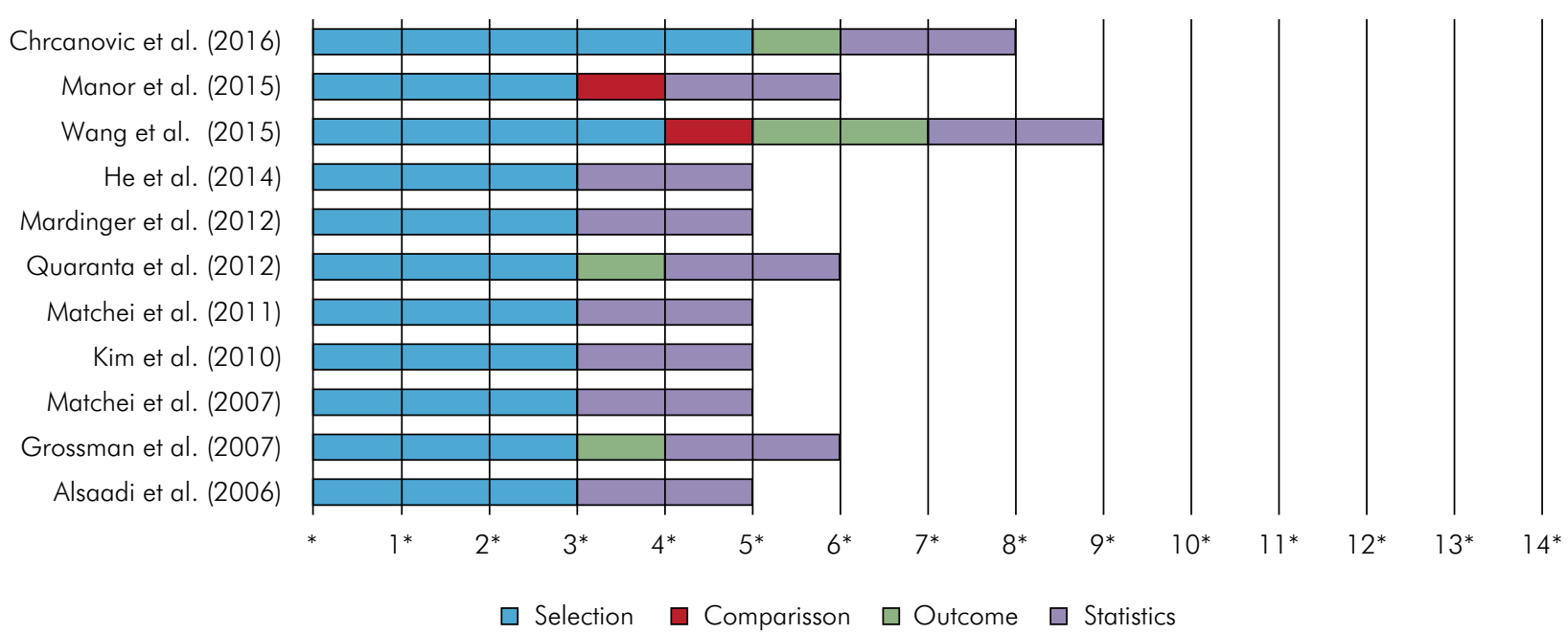

Figure 3. Methodological quality of included studies. Study quality was categorized as high ( 11 to 14 total star points), moderate (8 to 10 stars), or low (0 to 7 stars), according to a modified Newcastle-Ottawa Scales (NOS). ${ }^{30}$

in sites with two previous failures $(93.6 \%$ and $62.5 \%$, respectively; OR $=8.77(3.18-24.23)$. Finally, a metaanalysis comparing the survival rates of implants placed in sites with history of one and two implant failures ${ }^{18,10,23,25}$ revealed similar survival rates $(82.5 \%$ and $76.7 \%$, respectively; $\mathrm{OR}=1.52(0.61-3.78)$.

\section{Methodological quality of included studies}

Included studies received a 5- to 9-point score, with a mean of 5,91 points, and thus, were of low to moderate methodological quality due to their risk of bias (Figure 3). None of these studies reported on sample size calculations, training/calibration of examiners, management of confounders or independent blind assessment. Patients included in three studies ${ }^{18,25,26}$ were truly representative of patients that received dental implants in sites with previous implant failure in their centers. Patients included in other three studies ${ }^{19,20,23}$ were partially representative of patients treated in their center. Other studies failed to describe the derivation of the groups.

In all but one study, ascertainment of sites treated with dental implants was done using secure patient records. Quaranta et al. ${ }^{27}$ conducted clinical and radiographic examinations. Definitions of inclusion and exclusion criteria were clearly stated in seven studies. ${ }^{10,18,19,20,22,24,27}$ Definitions and assessment of implant failure were clearly reported in five studies. ${ }^{10,20,22,24,27}$ Finally, adequacy of follow-up of patients was only found in two studies. ${ }^{20,27}$

\section{Discussion}

Evidence based dentistry has had an increasing impact on oral care over the last years. Along these lines, this systematic review and meta-analysis provide a comprehensive assessment of the survival and success rates of implants inserted in sites with history of implant failure(s). We found that the survival rates of first implants ranged from 93\% to $99 \% 18,20,25$ and were in line to the data reported in the literature. ${ }^{1,2,3,4}$ Further, first implants presented survival rates higher than implants placed in sites with history of one or two implant failures. Moreover, implants placed in sites with one and two previous implant failures had similar survival rates.

Although some studies reported the time and causes of implant failure, most have failed to run separate survival analysis for replacement implants placed in sites with history of early and late implant failures. The three studies reporting exclusively on implants placed in sites with history of one early implant failure ${ }^{20,26,27}$ revealed a weighted implants survival rate of $91.8 \%$. However, no study reported on the outcomes of implants placed exclusively in sites with history of late failure. Finally, all studies failed to provide survival rates for replacement implants placed specifically in sites with history of biological, mechanical or iatrogenic implant failures. It is critical 
to note that the pathogeneses of the various types of implant failures are quite distinct. ${ }^{8,32}$ As such, distinct types of implant failures may differentially affect replacement implant outcomes.

Both patient- and implant-related factors can profoundly affect both the survival and clinical success of osseointegrated implants. Patients with systemic and environmental conditions known to compromise implant therapy outcomes were excluded from many of the studies included in this meta-analysis. 10,19,20,22,23,24,27 Exclusion of these patients precluded a more thorough evaluation of the risk factors associated with replacement implant failure and possibly resulted in higher replacement implant survival rates. Thus, the results from this metaanalysis must be interpreted with caution for patients with known risk factors.

A higher failure rate of implants placed in sites with history of implant failure was described for patients taking antidepressants and antithrombotic agents and in sites with poor bone quality and low quantity. ${ }^{18}$ Selective serotonin reuptake inhibitors (SSRI), a much common prescribed antidepressant, affects not only nervous tissue but may cause bone loss by inhibiting bone-remodeling process triggered by mechanical loading. ${ }^{33}$ Moreover, its use has already been associated with increased failure risk of dental implants placed in pristine bone (hazard ratio, 6.28). ${ }^{34}$ Concerning implant-related factors, two studies demonstrated treated-surface implants presented significantly higher survival rates than smooth machined implants. ${ }^{18,26}$ This result is in agreement with others that showed that rough-surface implants have better survival rates than machined implants placed in pristine bone. ${ }^{35}$

\section{References}

1. Adell R, Eriksson B, Lekholm U, Brånemark PI, Jemt T. Long-term follow-up study of osseointegrated implants in the treatment of totally edentulous jaws. Int J Oral Maxillofac Implants. 1990;5(4):347-59.

2. Lindquist LW, Carlsson GE, Jemt T. A prospective 15-year follow-up study of mandibular fixed prostheses supported by osseointegrated implants. Clinical results and marginal bone loss. Clin Oral Implants Res. 1996 Dec;7(4):329-36. https://doi.org/10.1034/j.1600-0501.1996.070405.x
Peri-implantitis is the major condition associated with late implant failure. Recent evidence demonstrated that peri-implantitis progresses in a non-linear accelerating pattern and that its onset occurs following three years of implant function. ${ }^{36}$ Thus, it is important to highlight that most included studies followed replacement implants for a period of one year or less. Hence, longer follow-ups are necessary to fully disclosure the incidence of late failures in replacement implants. Finally, the included studies are of low to moderate quality level and must be confirmed by high-quality studies.

\section{Conclusions}

Despite the low to moderate quality level of the published evidence. existing data indicate that replacement implants have moderate survival rates and can be considered as an approach in the treatment of edentulous patients. Larger prospective studies with well defined criteria for early and late implant failure, larger sample sizes and adequate follow up are necessary to confirm and expand on these results.

\section{Footnotes}

$\S$ Comprehensive Meta-Analysis software, v.3.3.070, Biostat, New Jersey, USA

\section{Acknowledgements}

No external funding, apart from the support of the authors' institution, was available for this study. The authors have stated explicitly that there are no conflicts of interest in connection with this article.

\footnotetext{
3. Roos-Jansåker AM, Lindahl C, Renvert H, Renvert S. Nine- to fourteen-year follow-up of implant treatment. Part I: implant loss and associations to various factors. J Clin Periodontol. 2006 Apr;33(4):283-9. https://doi.org/10.1111/i.1600-051X.2006.00907.x

4. Alsaadi G, Quirynen M, Komárek A, Steenberghe D. Impact of local and systemic factors on the incidence of oral implant failures, up to abutment connection. J Clin Periodontol. 2007 Jul;34(7):610-7. https://doi.org/10.1111/i.1600-051X.2007.01077.x
} 
5. Berglundh T, Persson L, Klinge B. A systematic review of the incidence of biological and technical complications in implant dentistry reported in prospective longitudinal studies of at least 5 years. J Clin Periodontol. 2002;29(s3 Suppl 3):197212. https://doi.org/10.1034/i.1600-051X.29.s3.12.x

6. Anner R, Grossmann Y, Anner Y, Levin L. Smoking, diabetes mellitus, periodontitis, and supportive periodontal treatment as factors associated with dental implant survival: a long-term retrospective evaluation of patients followed for up to 10 years. Implant Dent. 2010 Feb;19(1):57-64. https://doi.org/10.1097/ID.0b013e3181bb8f6c

7. Duyck J, Naert I. Failure of oral implants: aetiology, symptoms and influencing factors. Clin Oral Investig. 1998 Sep;2(3):102-14. https://doi.org/10.1007/s007840050054

8. Esposito M, Hirsch JM, Lekholm U, Thomsen P. Biological factors contributing to failures of osseointegrated oral implants. (I). Success criteria and epidemiology. Eur J Oral Sci. 1998 Feb;106(1):527-51. https://doi.org/10.1046/i.0909-8836..t01-2-.x

9. Quirynen M, De Soete M, Steenberghe D. Infectious risks for oral implants: a review of the literature.

Clin Oral Implants Res. 2002 Feb;13(1):1-19. https://doi.org/10.1034/i.1600-0501.2002.130101.x

10. Mardinger $O$, Ben Zvi Y, Chaushu G, Nissan J, Manor $Y$. A retrospective analysis of replacing dental implants in previously failed sites. Oral Surg Oral Med Oral Pathol Oral Radiol. 2012 Sep;114(3):290-3. https://doi.org/10.1016/j.tripleo.2011.07.010

11. Gonçalves TM, Campos CH, Garcia RC. Effects of implantbased prostheses on mastication, nutritional intake, and oral health-related quality of life in partially edentulous patients: a paired clinical trial. Int J Oral Maxillofac Implants. 2015 MarApr;30(2):391-6. https://doi.org/10.11607/jomi.3770

12. Fueki K, Igarashi Y, Maeda Y, Baba K, Koyano K, Sasaki $K$ et al. Effect of prosthetic restoration on masticatory function in patients with shortened dental arches: a multicentre study. J Oral Rehabil. 2016 Jul;43(7):534-42. https://doi.org/10.1111/joor.12387

13. Awad MA, Locker D, Korner-Bitensky N, Feine JS. Measuring the effect of intra-oral implant rehabilitation on health-related quality of life in a randomized controlled clinical trial. J Dent Res. 2000 Sep;79(9):1659-63. https://doi.org/10.1177/00220345000790090401

14. Awad MA, Lund JP, Shapiro SH, Locker D, Klemetti E, Chehade $\mathrm{A}$ et al. Oral health status and treatment satisfaction with mandibular implant overdentures and conventional dentures: a randomized clinical trial in a senior population. Int J Prosthodont. 2003 Jul-Aug;16(4):390-6.

15. Tajbakhsh S, Rubenstein JE, Faine MP, Mancl LA, Raigrodski AJ. Selection patterns of dietary foods in edentulous participants rehabilitated with maxillary complete dentures opposed by mandibular implant-supported prostheses: a multicenter longitudinal assessment. J Prosthet Dent. 2013 Oct;110(4):2528. https://doi.org/10.1016/S0022-3913(13)60371-6
16. Gates WD 3rd, Cooper LF, Sanders AE, Reside GJ, De Kok IJ. The effect of implant-supported removable partial dentures on oral health quality of life. Clin Oral Implants Res. 2014 Feb;25(2):207-13. https://doi.org/10.1111/clr.12085

17. Zembic A, Wismeijer D. Patient-reported outcomes of maxillary implant-supported overdentures compared with conventional dentures. Clin Oral Implants Res. 2014 Apr;25(4):441-50. https://doi.org/10.1111/clr.12169

18. Chrcanovic BR, Kisch J, Albrektsson T, Wennerberg A. Survival of dental implants placed in sites of previously failed implants. Clin Oral Implants Res. 2017 Nov;28(11):1348-53. https://doi.org/10.1111/clr.12992

19. Manor Y, Oubaid S, Mardinger O, Chaushu $G$, Nissan J. Characteristics of early versus late implant failure: a retrospective study. J Oral Maxillofac Surg. 2009 Dec;67(12):2649-52. https://doi.org/10.1016/i.joms.2009.07.050

20. Wang F, Zhang Z, Monje A, Huang W, Wu Y, Wang G. Intermediate long-term clinical performance of dental implants placed in sites with a previous early implant failure: a retrospective analysis. Clin Oral Implants Res. 2015 Dec;26(12):1443-9. https://doi.org/10.1111/clr.12485

21. He J, Shang YW, Deng CF, Shang DH, Zhang C, Wang DN et al. [A clinical retrospective analysis of dental implants replaced in previously failed sites]. Shanghai Kou Qiang Yi Xue. 2014 Apr;23(2):196-200. Chinese.

22. Machtei EE, Horwitz J, Mahler D, Grossmann Y, Levin L. Third attempt to place implants in sites where previous surgeries have failed. J Clin Periodontol. 2011 Feb;38(2):195-8. https://doi.org/10.1111/j.1600-051X.2010.01629.x

23. Kim YK, Park JY, Kim SG, Lee HJ. Prognosis of the implants replaced after removal of failed dental implants. Oral Surg Oral Med Oral Pathol Oral Radiol Endod. 2010 Sep;110(3):281-6. https://doi.org/10.1016/j.tripleo.2010.01.031

24. Machtei EE, Mahler D, Oettinger-Barak O, Zuabi O, Horwitz J. Dental implants placed in previously failed sites: survival rate and factors affecting the outcome. Clin Oral Implants Res. 2008 Mar;19(3):259-64. https://doi.org/10.1111/j.1600-0501.2007.01466.x

25. Grossmann Y, Levin L. Success and survival of single dental implants placed in sites of previously failed implants. J Periodontol. 2007 Sep;78(9):1670-4. https://doi.org/10.1902/jop.2007.060516

26. Alsaadi G, Quirynen M, van Steenberghe D. The importance of implant surface characteristics in the replacement of failed implants. Int J Oral Maxillofac Implants. 2006 Mar-Apr;21(2):270-4.

27. Quaranta A, Cicconetti A, Battaglia L, Piemontese M, Pompa G, Vozza I. Crestal bone remodeling around platform switched, immediately loaded implants placed in sites of previous failures. Eur J Inflamm. 2012 May; 10(2):115-22. https://doi.org/10.1177/1721727X120100\$222 
28. Quaranta A, Perrotti V, Piattelli A, Piemontese M, Procaccini M. Implants placed in sites of previously failed implants: a systematic review. Implant Dent. 2014 Jun;23(3):311-8. https://doi.org/10.1097/ID.0000000000000094

29. Liberati A, Altman DG, Tetzlaff J, Mulrow C, Gøtzsche PC, loannidis JP et al. The PRISMA statement for reporting systematic reviews and meta-analyses of studies that evaluate health care interventions: explanation and elaboration. PLoS Med. 2009 Jul;6(7):e1000100. https://doi.org/10.1371/journal.pmed.1000100

30. Chambrone L, Mandia J Jr, Shibli JA, Romito GA, Abrahao M. Dental implants installed in irradiated jaws: a systematic review. J Dent Res. 2013 Dec;92(12 Suppl):119S-30S. https://doi.org/10.1177/0022034513504947

31. Albrektsson T, Zarb G, Worthington P, Eriksson AR. The long-term efficacy of currently used dental implants: a review and proposed criteria of success. Int J Oral Maxillofac Implants. 1986;1(1):11-25.

32. Tonetti MS, Schmid J. Pathogenesis of implant failures. Periodontol 2000. 1994 Feb;4(1):127-38. https://doi.org/10.1111/j.1600-0757.1994.tb00013.x
33. Sibilia V, Pagani F, Dieci E, Mrak E, Marchese M, Zarattini $G$ et al. Dietary tryptophan manipulation reveals a central role for serotonin in the anabolic response of appendicular skeleton to physical activity in rats. Endocrine. 2013 Dec;44(3):790-802. https://doi.org/10.1007/s12020-013-9962-6

34. Wu X, Al-Abedalla K, Rastikerdar E, Abi Nader S, Daniel NG, Nicolau B et al. Selective serotonin reuptake inhibitors and the risk of osseointegrated implant failure: a cohort study. J Dent Res. 2014 Nov;93(11):1054-61. https://doi.org/10.1177/0022034514549378

35. Khang W, Feldman S, Hawley CE, Gunsolley J. A multi-center study comparing dual acid-etched and machined-surfaced implants in various bone qualities. J Periodontol. 2001 Oct;72(10):1384-90. https://doi.org/10.1902/jop.2001.72.10.1384

36. Derks J, Schaller D, Håkansson J, Wennström JL, Tomasi C, Berglundh T. Peri-implantitis - onset and pattern of progression. J Clin Periodontol. 2016 Apr;43(4):383-8. https://doi.org/10.1111/jcpe.12535 